\title{
Modulation of immune cells and Th1/Th2 cytokines in insulin-treated type 2 diabetes mellitus.
}

\author{
Magloire Pandoua Nekoua ${ }^{1}$, Rufine Fachinan ${ }^{1}$, Amidou K Atchamou ${ }^{1}$, Odilon Nouatin ${ }^{2}$, \\ Daniel Amoussou-Guenou ${ }^{3}$, Marcellin K Amoussou-Guenou ${ }^{4}$, Kabirou Moutairou ${ }^{1}$, Akadiri Yessoufou ${ }^{1}$
}

1. Laboratory of Cell Biology and Physiology, Institute of Applied Biomedical Sciences (ISBA) and Faculty of Sciences and Techniques, University of Abomey-Calavi, 01 BP 526 Cotonou, Bénin.

2. Centre d'Etude et de Recherche sur le Paludisme associé à la Grossesse et à l'Enfance IRD/UMR-216, Cotonou, Bénin.

3. Service of Internal Medicine, Centre National Hospitalier et Universitaire (CNHU) and Faculty of Health

Sciences (FSS); Cotonou, Bénin.

4. Service of Radio-immuno-assay (SERID), Faculty of Health Sciences (FSS); Cotonou, Bénin.

\begin{abstract}
Background: The role of the immune system in insulin resistance associated with type 2 diabetes has been suggested.

Objectives: We assessed the profile of Th1/Th2 cytokines along with the frequencies of immune cells in insulin-treated type 2 diabetic patients (T2DP).

Methods: 45 T2D patients and 43 age-matched healthy subjects were selected. Serum concentrations of T-helper type 1 (Th1) and Th2 cytokines and the frequencies of innate and adaptive immunity cells were assessed.

Results: T2DP were hyperglycemic and showed high level of insulin, normal levels of triglycerides and total-cholesterol and without any change in HDL-cholesterol.Compared to healthy subjects, T2DP exhibited significant decreased frequencies of neutrophils, without any change in monocytes, eosinophils and natural killer cells. The percentages of total lymphocytes (CD3+) and CD8+-T-cells decreased whereas those of regulatory T-cells increased without any change in CD4+ T-cells in T2DP. Interestingly, the frequencies of effector CD4+-T and B-cells increased in T2DP. Serum concentrations of IL-2, IFN- $\gamma$ and IL-4 decreased while IL-10 significantly enhanced in T2DP, suggesting a differentiation of CD4+T helper cells towards IL-10-producing-Teff-cells in these patients.

Conclusion: Insulin-treated type 2 diabetes is associated with anti-inflammatory profile consistent with differentiation of CD4+-Th-cells towards IL-10-producing-Teff-cells, concomitant with increased frequencies of Treg and B-cells, and this may probably offer prevention against certain infections or autoimmune/inflammatory diseases.
\end{abstract}

Keywords: Type 2 diabetes, Insulin, Immune cells, Th1/Th2 polarization.

DOI: http://dx.doi.org/10.4314/ahs.v16i3.11

Cite as: Nekoua MP, Fachinan R, Atchamou AK, Nouatin O, Amoussou-Guenou D, Amoussou-Guenou MK, Moutairou K, Yessoufou A. Modulation of immune cells and Th1/Th2 cytokines in insulin-treated type 2 diabetes mellitus. Afri Health Sci 2016;16(3): 712-724. DOI: bttp://dx.doi.org/10.4314/abs.v16i3.11.

\section{Introduction}

Type 2 diabetes mellitus is one of the most important epidemic diseases in the world. It accounts for $90 \%$ of cases

\section{Corresponding author:}

Akadiri Yessoufou,

University of Abomey-Calavi,

Laboratory of Cell Biology and Physiology,

Institute of Applied Biomedical Sciences (ISBA),

01 BP 918 Cotonou, Bénin ;

Tel. + 22997696083

Fax. + 22921331467 ;

E-mail: akadiri.yessoufou@gmail.com, yeskad2001@yahoo.fr

African Health Sciences Vol 16 Issue 3, September 2016 of diabetes ${ }^{1-3}$. Type 2 diabetes is a group of metabolic disorders characterized by chronic hyperglycemia associated with abnormalities of the metabolism of carbohydrates, fats and proteins resulting in insulin resistance ${ }^{1-3}$. It is mainly the result of sedentary lifestyle, excess body weight and physical inactivity ${ }^{3}$.

Besides, evidence is now arising and suggesting the pathological role of immune system in the chronic inflammation and insulin resistance observed in type 2 diabetes. Indeed,type 2 diabetes results from generalized activation of innate immune system, in which there is a chronic cytokine-mediated inflammation ${ }^{4-6}$. These cytokines act on liver, adipose tissue, brain, and pancreatic 
$\beta$-cells leading to a disrupted lipid metabolism which is the main risk factor for atherosclerosis, obesity and insulin resistance associated with type 2 diabetes $^{7,8}$. We have previously demonstrated, in human and animal studies, the implication of T-cell differentiation through Th1/ Th2 cytokines in the modulation of gestational diabetes and macrosomia ${ }^{9-13}$. Nowadays, it is well known that naïve Th0 cell can differentiate into specific Th subsets (Th1, Th2, Th9, Th17, Th22, Treg,...) under the influence of cytokines, which on one hand can promote differentiation into a specific subset or on the other hand block differentiation towards a functionally-opposing subset ${ }^{14}$. Th1 cells, producing pro-inflammatory cytokines (IL-2, IL-12, IFN- $\gamma$ ), support cell-mediated immunity and as a consequence promote inflammation, cytotoxicity, and delayed-type hypersensitivity; whereas Th2 cells, secreting anti-inflammatory cytokines (IL-4, IL-5, IL-13), support humoral immunity and down-regulate the inflammatory actions of Th1 cells ${ }^{15-17}$. Other studies have shown the role of adaptive immunity in insulin resistance observed in obesity-induced type 2 diabetes $^{18-22}$. Indeed, obesity modulates the balance between the pro-inflammatory CD4+ T lymphocyte subpopulations (Th1 and Th17) and anti-inflammatory (Th2), and the increase of CD8+ cytotoxic $\mathrm{T}$ cells and production of pro-inflammatory cytokines leading to the activation and infiltration of macrophages in adipose tissue ${ }^{18-23}$. It has been reported that CD4+CD25+ regulatory $T$ cells can suppress inflammation of adipose tissue and play a protective role against the insulin resistance induced by obesity ${ }^{24-26}$. Of note, regulatory $\mathrm{T}$ (Treg) cells were initially defined as a subpopulation of suppressor $\mathrm{T}$ cells that mediate immune tolerance to self and foreign antigens by suppressing autoreactive CD4+ or CD8+ $\mathrm{T}$ cells ${ }^{27,28}$. Several types of Treg cells have been identified and characterized as natural and adaptive/inducible Treg cells ${ }^{29}$. Natural Treg cells that originate in the thymus are self-reactive ${ }^{29}$, and possess ability to suppress the activation of effector T cells in a cell-contact-dependent manner, cytokine-independent (interleukin-10, (IL-10)-independent, and transforming growth factor, (TGF- $\beta$ )-independent manner ${ }^{27,28}$. However, the inducible Treg cells (iTreg) arise in the periphery, either during an immune response or after encountering tolerogenic dendritic cells ${ }^{30}$. They suppress the activation of effector $\mathrm{T}$ cells in a cytokine-dependent manner: TGF- $\beta$ for Th3 cells and IL-10 for T regulatory 1 cells $^{31}$. Understanding the relationship between $\mathrm{T}$ cell cy- tokines and immune cell subtypes may reveal the clinically relevant pathways that contribute to inflammation and insulinresistance observed in T2D. Thus, the present study was undertaken to investigate the profile of Th1/ Th2 cytokines along with the frequencies of leukocyte subpopulations of innate and adaptive immune systems in insulin-treated type 2 diabetic patients.

\section{Subjects and methods Patients}

Forty five insulin-treated type 2 diabetic patients between 30 and 55 years of age were selected from type 2 diabetic population at the Principal Insulin Bank (Diabetic Centre) of Cotonou(Benin) where medical records were screened by specialist clinicians. Diabetes was diagnosed according to WHO criteria. They were non-obese or formally obese people, with or without family records of diabetes, and in whom oral treatments, diet management and physical exercises were not favourable. They were all on insulin treatment. No patients received lipid lowering medications. None of them had shown renal failure evaluated by renal impairment such as abnormal creatinemia, uraemia and macroalbuminuria. As controls, forty three healthy subjects were selected from the general healthy community in same study area. Control subjects and diabetic patients were matched with respect to age and body mass index (BMI) as determined by the weight and height of patients.

Control subjectss had no family history of diabetes and showed normal fasting glycaemia measured twice at inclusion. As inclusion criteria, all participants were nonsmokers, had no significant history of other illness, no pregnancy, no clinical signs of infectious disease, no hepatitis B viral, no HIV and no malaria infection after blood sample tests. They lived in Cotonou (Littoral province, Benin) and within $5 \mathrm{~km}$ around the city, where the endemicity of helminth infections has not been shown $n^{32,33}$. The anthropometric and clinical data of diabetic and control subjects are shown in Table 1. Informed written consent was obtained from all individual participants included in the study. The study was conducted in accordance with the Declaration of Helsinki (1964, as revised in Edinburgh 2000). The protocol was approved by the Ethics Committee on Research of the Institute of Applied Biomedical Sciences of Cotonou, Benin under the number Dec.n075/CER/ISBA-2015. 


\section{Blood samples}

From each patient or control subject, fasting venous blood samples were collected in tubes containing either EDTA or fluoride oxalate, or nothing to obtain respectively plasma and serum by low-speed centrifugation (1000 g for $10 \mathrm{~min}$ ). Plasma from fluoride oxalate tube was immediately used for blood glucose determinations. Serum was distributed in aliquots and frozen at $-80^{\circ} \mathrm{C}$ for future determinations of insulin, lipids and $\mathrm{T}$ cell $\mathrm{cy}-$ tokine concentrations. Whole blood samples of EDTA tubes were used for immune cell subtype phenotyping. The quality of serum and plasma was checked visually to ensure lack of turbidity and hemolysis that may interfere with the assay results.

\section{Determination of plasma glucose and HbA1c and serum insulin and lipid concentrations}

Plasma fasting glucose was determined by the glucose oxidase method using a glucose analyzer (Beckman Instruments, Fullerton, CA). Glycosylated haemoglobin (HbA1c) levels were determined in the whole blood. HbA1c concentration was calculated using a percentage of total haemoglobin, according to the manufacturer's instructions (Ref. 41190, Labkit Chemelex SA, Barcelona, Spain). Serum triglycerides, total- and HDL-cholesterol concentrations were determined by using enzymatic methods, according to the instructions furnished with the kit (Boehringer, Mannheim, Germany). Serum insulin concentrations were determined by using the Insulin IRMA kit (Ref. IM3210; Immunotech, Beckman Coulter Inc., Fullerton, CA) with a detection limit of $0.5 \mathrm{IU} / \mathrm{ml}$. The interassay coefficients of variability were 3.3 and $4 \%$, respectively, for the concentrations 13 and $54 \mathrm{IU} / \mathrm{ml}$.

\section{Immune cell phenotyping}

The frequencies of innate immunity cells (monocytes, polynuclear eosinophils PNE, polynuclear neutrophils PNN, natural killer NK cells) and adaptive immunity cells (total lymphocytes, CD4+ T helper cells, CD8+ cytotoxic $\mathrm{T}$ cells, effector $\mathrm{T}$ cells and $\mathrm{B}$ cells) were determined in the whole blood by immunostaining with different specific monoclonal antibodies (mAbs) combinations. Briefly, whole blood was stained with appropriate combination of specific $\mathrm{mAbs}$ to allow identification of $\mathrm{T}$ cell sub-populations. After incubation with the $\mathrm{mAbs}$ for $30 \mathrm{~min}$ at $4^{\circ} \mathrm{C}$ in the dark, cells were washed and fixed with FACS lysing solution (BD Pharmigen). Anti-CD3FITC/ anti-CD4-PerCP/ anti-CD8-PE/ anti-CD25-PE/ anti-CD127-FITC/ anti-Foxp3-APC (BD Pharmigen) were used for T cell labeling, anti-CD19-FITC (BD Pharmigen) for B lymphocytes, anti-CD16-PE/anti-CD56APC (BD Pharmigen) for NK cells, anti-CD14-FITC (BD Pharmigen) for monocytes and anti-CD16-PE (BD Pharmigen) for polynuclear cells. Anti-CD4-PerCP, antiCD25-PE and anti-CD127-FITC were used for Treg cell labeling. Anti-Foxp3-APC (BD Pharmigen) was added for intracellular staining of Treg cells according to the manufacturer's instructions, after permeabilisation and fixation with PermFix (BD Pharmigen). Of noteworthy, we used a definition of regulatory $\mathrm{T}$ cells (Treg, CD4+CD25+CD127-) for a sub-population of CD4+ T cells that highly expressed Foxp3, thereby distinguishing it from the sub-population defined as effector $\mathrm{T}$ cells (Teff, CD4+,CD25+,CD127+) (data not shown). The cells were finally resuspended in $300 \mu \mathrm{l}$ of staining buffer, acquired using FACSCalibur four-colour flow cytometer (BD Pharmigen, France) and analyzed using CellQuest Pro or Flowjo 7.6 software (BD Pharmigen, France). Gating strategies for immune cell phenotyping are shown in Figure 1a-g. 
Figure 1
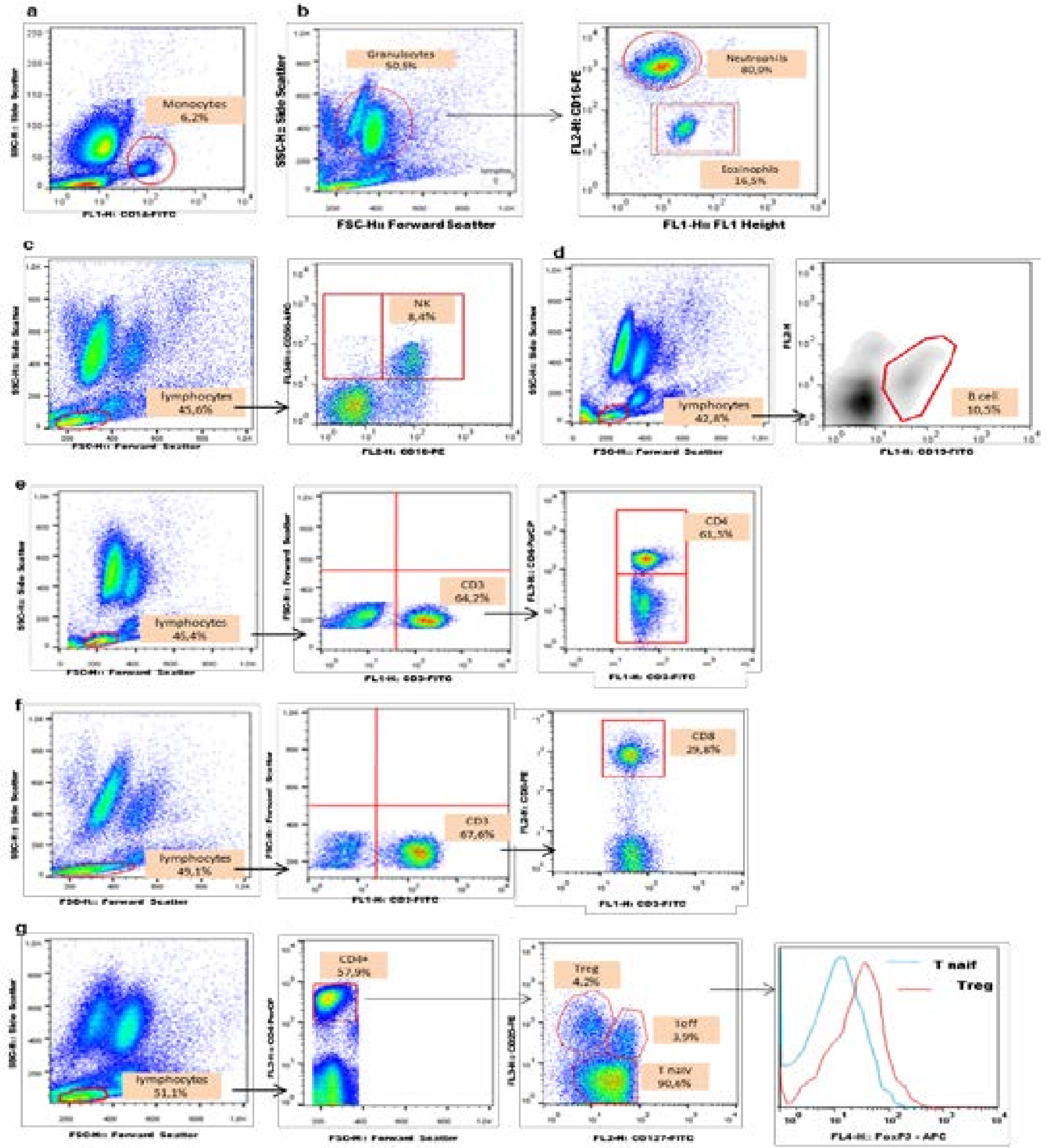

Figure 1. Cytometry-based gating for definition of phenotypes. (a) Monocytes (CD14+) were gated from mononuclear population in blood cells. (b) Eosinophils and neutrophils (CD16+) were gated from granulocyte population. (c) NK cells, non-T lymphocytes (CD16+CD56+) were gated from the total lymphocyte population. (d) B cells (CD19+) were gated from total lymphocytes. (e) CD4+ and (f) CD8+ T cells were gated from total lymphocyte population (CD3+). (g) Gating strategies for Treg (CD4+CD25+CD127-) and Teff $(\mathrm{CD} 4+\mathrm{CD} 25+\mathrm{CD} 127+)$. Cell frequencies were determined as a percentage of total lymphocytes (CD3+), and relative Foxp3 expression level determined as a function of Foxp3 expression by CD4+ T cells 
Determination of serum Th1/Th2 cytokine concentrations

Determination of cytokine concentrations was performed on serum samples that were stored at $-80^{\circ} \mathrm{C}$. Repeated freeze-thaw cycles were avoided. Cytokines were quantified by ELISA, using BioLegend human Th1/Th2 ELISA MAX ${ }^{\mathrm{TM}}$ Deluxe set kits (BioLegend, San Diego, CA, USA), according to the manufacturer's instructions.

\section{Statistical analyses}

Data analyses were performed using STATA/MP 11.2 (StataCorp, College Station, TX, USA) and Graph Pad Prisme 5.0 (Graph Pad Inc, CA, USA). Values are means \pm SEM or medians \pm IQR. The non-parametric MannWhitney $\mathrm{U}$ test was employed for the comparison of cell frequencies and cytokine levels between type 2 diabetic patients and control subjects. Anthropometric, clinical and biochemical data were compared between type 2 diabetic patients and control subjects, using Student's $t$ test. Differences were considered significant when $\mathrm{p}<0.05$.

\section{Results}

\section{Blood glucose, serum insulin and lipid levels}

Insulin-treated T2D patients were hyperglycemic and showed high level of insulin as compared to healthy control subjects (Table 1). Although insulin-treated T2D patients were normolipidemic, they showed significant low levels of TG and total-cholesterol, as compared to control subjects; HDL-cholesterol did not differ between both groups (Table 1).

Table 1: Anthropometric and biochemical data of subjects

\begin{tabular}{lcc}
\hline & $\begin{array}{c}\text { Control subjects } \\
(\mathrm{n}=43)\end{array}$ & $\begin{array}{c}\text { Type } 2 \text { diabetic patients } \\
(\mathrm{n}=45)\end{array}$ \\
\hline Male/female ratio & $23 / 20$ & $21 / 24$ \\
Age & $30-54 \mathrm{yr}$ & $30-55 \mathrm{yr}$ \\
BMI $\left(\mathrm{kg} / \mathrm{m}^{2}\right)$ & $25.19 \pm 1.90$ & $26.38 \pm 0.92$ \\
Duration of disease (years) & - & $9.9 \pm 2.3$ \\
Insulin treatment $(\%$ patients & $\mathrm{No}$ & \\
receiving insulin treatment) & & Yes $(100 \%)$ \\
& $5.05 \pm 0.17$ & \\
Fasting glucose $(\mathrm{mM})$ & $4.25 \pm 0.25$ & $9.55 \pm 1.11 * *$ \\
HbA1C $(\%)$ & $5.46 \pm 0.77$ & $9.57 \pm 1.56^{* *}$ \\
Insulinemia $(\mu \mathrm{UI} / \mathrm{ml})$ & $5.33 \pm 0.33$ & $10.93 \pm 0.64 * *$ \\
Urea $(\mathrm{mM})$ & $95.38 \pm 6.31$ & $5.49 \pm 0.17$ \\
Creatinemia $(\mu \mathrm{M})$ & $5.64 \pm 0.41$ & $98.30 \pm 6.10$ \\
Total cholesterol $(\mathrm{mM})$ & $1.63 \pm 0.03$ & $4.35 \pm 0.36^{*}$ \\
HDL-cholesterol $(\mathrm{mM})$ & $1.23 \pm 0.13$ & $1.55 \pm 0.05$ \\
Triglycerides $(\mathrm{mM})$ & $0.83 \pm 0.11^{*}$ \\
\hline
\end{tabular}

BMI: Body Mass Index; HDL: High Density Lipoproteins; HbA1c: glycosylated hemoglobin. Values are means \pm SEM. $\mathrm{n}=43$ healthy control subjects; $n=45$ type 2 diabetic patients. ${ }^{*} p<0.05$ and $* * p<0.01$ indicate significant difference between type 2 diabetic patients and healthy control subjects. Ranges of normal values: Fasting glucose: 3.88-6.10 mM (0.7-1.10 g/L); Totalcholesterol: 3.23-6.46 mM (1.25-2.50 g/L) ; HDL-cholesterol: 1.16-1.94 mM (0.45-0.75 g/L); Triglycerides: 0.57-1.71 mM (0.50$1.50 \mathrm{~g} / \mathrm{L})$; Urea: 2.50-7.49 mM (0.15-0.45 g/L) ; Creatinine: 53.04-123.76 $\mu \mathrm{M}$ (6-14 mg/L) ; HbA1c: 4-6 \% ; Insulin: $1.21-14.5$ $\mu \mathrm{Ul} / \mathrm{ml}$.

Immune cell frequencies are modified in type 2 diabetes

General analysis revealed that mononuclear cells declined while polynuclears did not change between insulin-treat- ed T2D patients and healthy control subjects (Figure 2ab). The frequencies of polynuclear neutrophils decreased while those of monocytes, polynuclear eosinophils and natural killer cells did not change when comparing T2D patients to control subjects (Figure 2c-f). 
Figure 2

Control subjects

Eod Type 2 diabetic patients
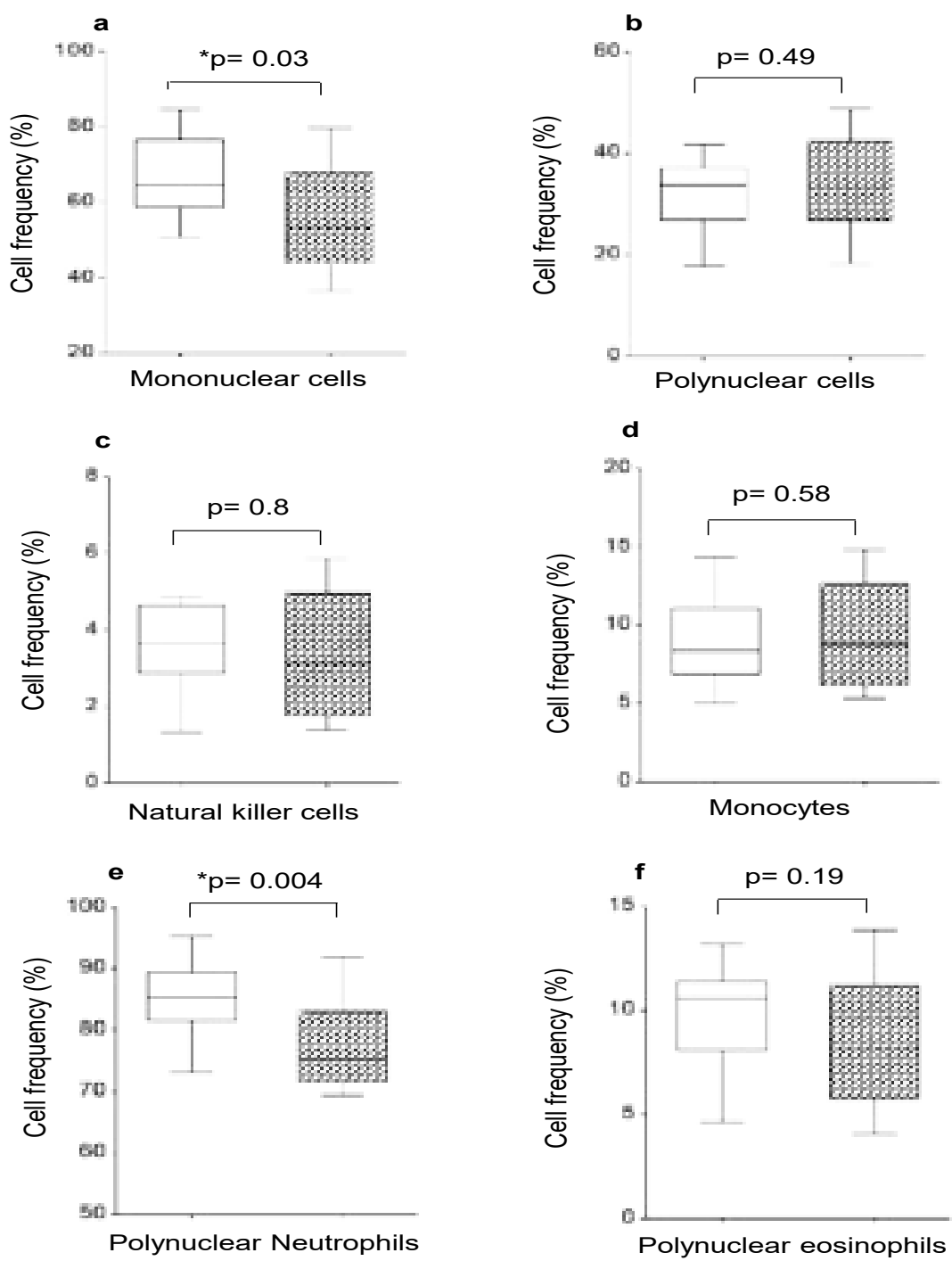

Figure 2. Frequencies (\%) of innate immunity cells in type 2 diabetic patients and control subjects. Cells were stained, as described in Materials and Methods section, in whole blood with appropriate combination of specific monoclonal antibodies to allow identification of cell sub-populations. (a) Total mononuclear cells; (b) Total polynuclear cells; (c) Natural killer cells ; (d) Monocytes ; (e) Polynuclear neutrophils ; (f) Polynuclear eosinophils. Cells were acquired using FACSCalibur four-colour flow cytometer (BD Pharmigen, France) and analyzed using CellQuest Pro or FlowJo 7.6 software (BD Pharmigen, France). Values are medians \pm IQR. $\mathrm{n}=43$ healthy control subjects; $\mathrm{n}=45$ type 2 diabetic patients. ${ }^{*} \mathrm{p}<0.05$ or ${ }^{* *} \mathrm{p}<0.01$ indicate significant difference between type 2 diabetic patients and healthy control subjects.

The frequencies of total lymphocytes declined in insulintreated T2D patients compared to control subjects, as shown in Figure 3a-b. Besides, CD8+ cytotoxic T cell frequencies decreased (Figure 3d) in T2D patients whereas there was no change in the frequency of CD4+ Th cells be- tween both groups (Figure 3c). However, the frequencies of effector CD4+ $\mathrm{T}$ cells (Teff, CD4+CD25+CD127+), regulatory $\mathrm{T}$ cells (Treg, CD4+CD25+CD127-) and $\mathrm{B}$ cells were significantly higher in insulin-treated T2D patients than in healthy control subjects (Figure 3e-f-g). 
Figure 3
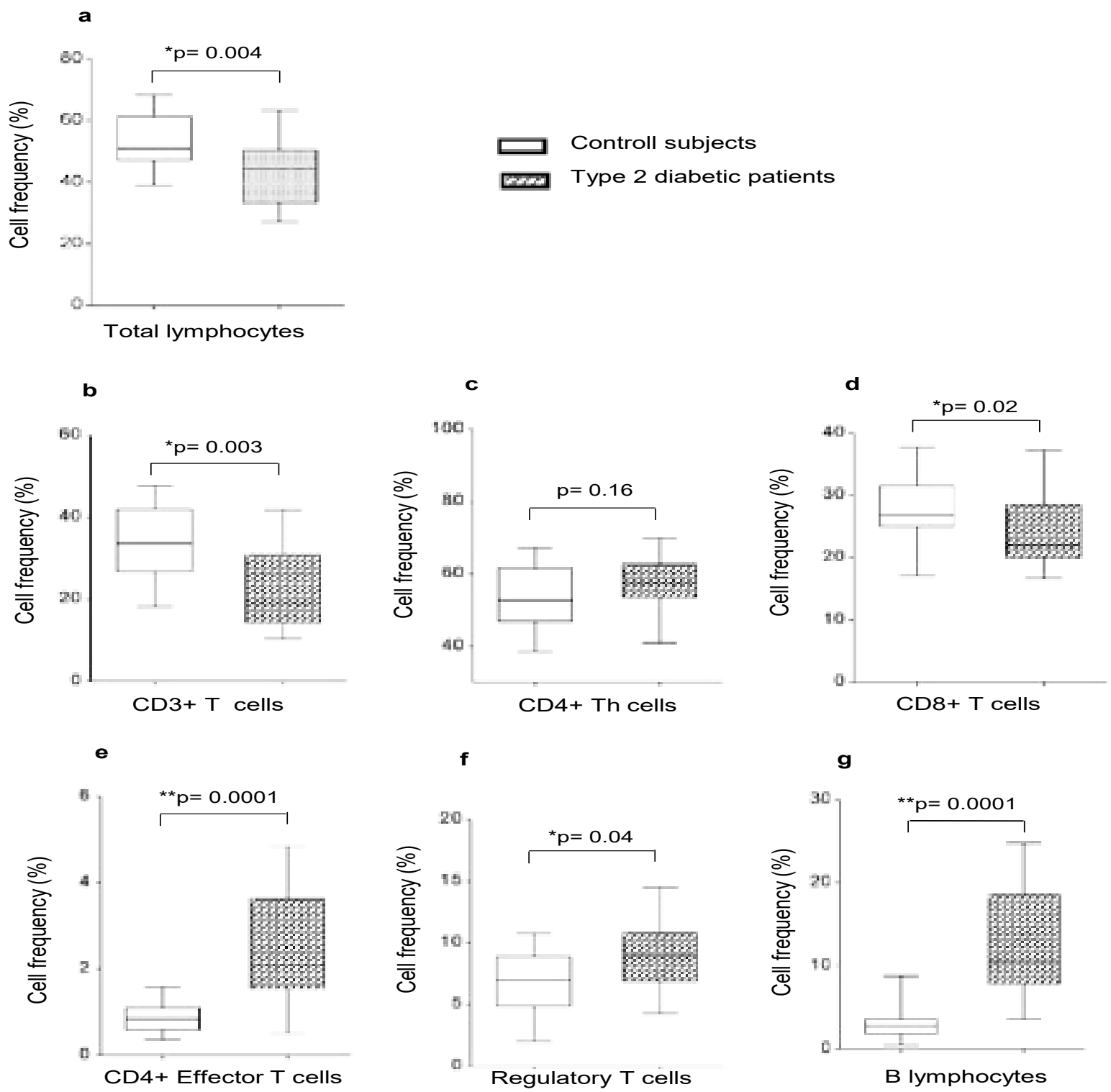

Figure 3. Frequencies (\%) of adaptive immunity cells in type 2 diabetic patients and control subjects. Cells were stained, as described in Materials and Methods section, in whole blood with appropriate combination of specific monoclonal antibodies to allow identification of cells sub-populations. (a) Total lymphocytes; (b) $\mathrm{CD}^{+} \mathrm{T}$ cells; (c) Total $\mathrm{CD}^{+}$cells; (d) $\mathrm{CD}^{+} \mathrm{T}$ cells. (e) Effector CD4+T cells $\left(\mathrm{CD} 4^{+} \mathrm{CD} 25^{+} \mathrm{CD}^{2} 7^{+}\right.$); (f) Regulatory $\mathrm{T}$ cells (Treg, $\mathrm{CD}^{+} \mathrm{CD}^{2} 5^{+} \mathrm{CD}^{127^{-}}$); (g) B 1ymphocytes. Cells were acquired using FACSCalibur four-colour flow cytometer (BD Pharmigen, France) and analyzed using CellQuest Pro or FlowJo 7.6 software (BD Pharmigen, France). Values are medians \pm IQR. $\mathbf{n}=43$ healthy control subjects; $\mathbf{n}=45$ type 2 diabetic patients. $* \mathrm{p}<0.05$ or $* * \mathrm{p}<0.01$ indicate significant difference between type 2 diabetic patients and healthy control subjects.

\section{Type 2 diabetes modulates serum cytokine levels}

Serum IL-2 and IFN- $\gamma$ concentrations significantly diminished in insulin-treated T2D patients compared with control subjects (Figure 4a). Besides, IL-4 concentration decreased whereas that of IL-10 significantly enhanced in insulin-treated T2D patients compared with control subjects (Figure $4 \mathrm{~b}$ ). The Th1/Th2 ratios, determined as IL-2/IL-4, IL-2/IL-10, IFN- $\gamma /$ IL-4, and IFN- $\gamma /$ IL-10, demonstrated a shift towards IL-10-producing Teff cell phenotype in type 2 diabetic patients (Table 2). 
Table 2 : Ratios of serum Th1 and Th2 cytokine concentrations in subjects.

\begin{tabular}{|l|c|c|c|c|c|}
\hline & IL-2/IL-4 & IL-2/IL-10 & IFN- $\gamma / \mathrm{IL}-4$ & IFN- $\gamma / \mathrm{IL}-10$ & IL-4/IL-10 \\
\hline Control subjects & 2.16 & 1.49 & 5.91 & 4.07 & 0.69 \\
\hline Type 2 diabetics & $0.99^{\S}$ & $0.15^{\S}$ & $3.95^{\S}$ & $0.61^{\S}$ & $0.16^{\S}$ \\
\hline
\end{tabular}

"Th1/Th2 and Th2/Th2 (last column) ratios were shifted toward Th2 phenotype in insulin-treated T2D patients. Values are ratios of mean concentrations of serum cytokines $n=43$ healthy control subjects; $n=45$ type 2 diabetic patients. The symbol ( $(\mathbb{)})$ indicates significant difference between the two ratios".

\section{Figure 4}
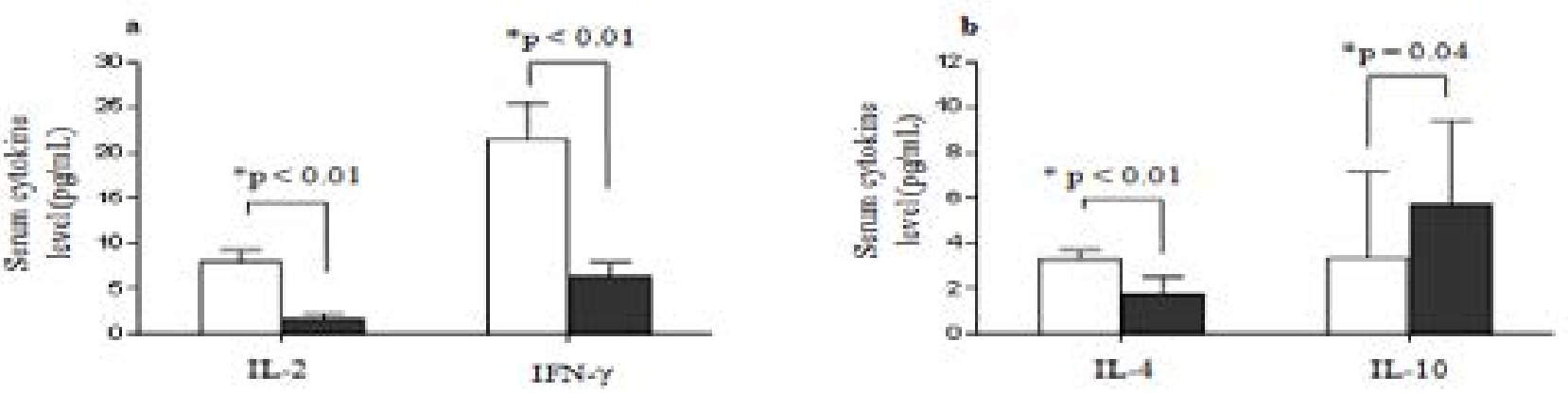

Figure 4. Serum Th1 (IL-2, INF- $\gamma$ ) and Th2 (IL-4, IL-10) cytokine concentrations in insulin-treated T2D patients and control subjects. Serum cytokine concentrations were determined as described in Materials and Methods. Values are medians \pm IQR. $n=43$ healthy control subjects; $n=45$ type 2 diabetic patients. *p values indicate significant difference between type 2 diabetic patients and healthy control subjects.

\section{Discussion}

The pathological role of the immune system in inflammation and insulin resistance observed in type 2 diabetes mellitus has been suggested ${ }^{4-6}$. Indeed, cytokines produced by $\mathrm{T}$ cells interfere with insulin signalling and have been implicated in insulin resistance in type 2 diabetes mellitus ${ }^{34}$. In the present study, we investigated the profile of T-cell derived Th1/Th2 cytokines along with percentages of innate and adaptive immune system cells in insulin-treated type 2 diabetic patients. It's well known that immune responses between male and female are not identical, since sexual hormones have been associated with prevalence, susceptibility, and severity of autoimmune diseases ${ }^{35,36 .}$ However, we would like to mention that our results did not reveal any difference between male and female individuals, either in diabetic group or control group.

In the present study, we observed that as compared to control subjects, insulin-treated T2D patients were hyperglycemic, have showed high level of insulin and high level of $\mathrm{HbA} 1 \mathrm{c}$, reflecting a poor control of diabetes ${ }^{37}$ and a decrease in insulin sensitivity in these patients, and this was in accordance with several reports ${ }^{38}$. Besides, we observed that insulin-treated T2D patients were normolipidemic, even though they showed significant low levels of TG and total-cholesterol, as compared to control subjects; HDL-cholesterol did not differ between both groups. In fact, insulin treatment could account for lowering the lipids (TG and total-chol) to normal levels in these patients, since insulin is known to enhance the activity of lipo- 
protein lipase, resulting in increase of lipid metabolism and then decreased levels of lipids ${ }^{39-41}$. Our results are in accordance with previous studies which have shown that insulin treatment could account for normalizing the levels of total cholesterol, TG and LDL-cholesterol in type II diabetic patients under poor metabolic control ${ }^{40}$. Interestingly, the lipid-lowering action of insulin, independent of glycemic control in T2D patients, appeared to be beneficial because of the role of dyslipidemia in the development of diabetic macrovascular disease such as vasculopathy ${ }^{41}$.

In the present study, we observed that serum IL-2, INF- $\gamma$ (Th1 cytokines) and IL-4 (Th2 cytokine) concentrations were down-regulated in insulin-treated T2D patients. Interestingly, the levels of IL-10 were increased in these diabetic patients. Our observations suggested that diminished concentrations of Th1 cytokines and increased IL-10 levels might contribute to the anti-inflammatory state observed in these patients. However, the diminished levels of circulating IL-4 mightay be responsible for the induction of diabetes mellitus. Our idea can be supported by the observations of Muller et al. ${ }^{42}$ who showed that diabetes susceptibility was more associated with reduction of IL-4 than with induction of IFN- $\gamma$ in islets of Balb/c diabetic mice. Similarly, Wood et al. ${ }^{16}$ have reported diminished expression of IL-4 in thymocytes of diabetic mice. Moreover, we have previously shown in clinical and experimental studies that a decrease of IL-4 may favour the onset of diabetic pregnancy in humans ${ }^{9}$ and animals ${ }^{10,11}$.

Type 2 diabetes has also been revealed as a chronic inflammatory disease promoted by changes in immune cell function and several studies have indicated that $\mathrm{T}$ cells are important mediators of inflammation in this disease ${ }^{18,}$ $19,24,25$. As far as innate immunity cells are concerned, we did not find significant differences in PNE, NK cells, and monocytes between insulin-treated T2D patients and controls, but we observed a tendency to a decrease in frequencies of PNE and NK cells in type 2 diabetic patients. Additionally to this trend towards a decrease of PNE and NK cells, polynuclear neutrophils significantly decreased in insulin-treated T2D patients, suggesting a reduction of innate immunity in these patients. However, it is important to mention that insulin-treated T2D patients exhibited a decline in their general immune defense system which was not only due to the decrease of poly- nuclear neutrophils, but also to the significant decrease of total mononuclear cells (as shown in the Fig 2a), mainly revealed by the significant reduction of total lymphocytes (Fig 3a, 3b, 3d). Regarding adaptive immunity cells,we have mentioned above that insulin-treated T2D patients showed declined frequency of total lymphocytes when compared to control subjects. Specifically, the decrease of total lymphocytes was revealed by the diminished percentages of circulating CD3 $+\mathrm{T}$ and $\mathrm{CD} 8+$ cytotoxic $\mathrm{T}$ cells and no change in the frequency of $\mathrm{CD} 4+\mathrm{T}$ cells between both groups. Similar results have been reported by Nishimura et al. ${ }^{18}$ who have observed a lower CD $8+\mathrm{T}$ cell counts in peripheral blood from ob/ob mice. One hypothesis to explain the low number of circulating CD8+ T cell in T2D patients, in ourthis study, could be a preferential relocation of these cells in adipose tissue ${ }^{18}$. Indeed, it has been reported a decreased number of peripheral CD8+ T cells and an increased infiltration of these cells in adipose tissue of ob/ob mice which contribute tomacrophage recruitment and adipose tissue inflammation in obesity and insulin resistance ${ }^{18,24}$. Thus, the concomitant reduction of innate immunity and decline of total CD3+ lymphocytes and CD8+ T cells in insulin-treated T2D patients might suggest a decreased level of generalimmune defense system (see below) ${ }^{15,16}$.

Recent data have supported the protective role of Treg cells against inflammation inadipose tissue and insulin resistance observed during obesity and type 2 diabetes ${ }^{24,26}$. In the present study, the concomitant increase of Treg cell frequency with the decline of total lymphocytes in insulintreated T2D patients reinforces our hypothesis of a low immune defense system in these patients ${ }^{15,16}$. Our results did not support those obtained by Zeng et al. 43who have observed that peripheral induced CD4+Foxp3+Helios(-) Treg cells were decreased in T2D patients. JagannathanBogdan et al. ${ }^{19}$ have also observed that T2D patients had decreased percentages of CD4+ Treg cells. Be that as it may, our study shown increased frequencies of Treg cells in T2D patients and, this is consistent with anti-inflammatory profile of these patients and might be partially explained by their insulin treatment. Indeed, it has been well established that insulin exerts anti-inflammatory activity through the inhibition of the production of proinflammatory cytokines by macrophages ${ }^{44-46}$. It is thus interesting to observe that insulin-treated T2D patients have shown decreased levels of pro-inflammatory Th1 
cytokines (IL-2/IFN- $\gamma$ ). Similarly, Dimitriadis et al. ${ }^{47}$ have shown in human studies that high insulin resulted in thereduction of infiltration and accumulation of macrophages in the tissues. Other investigators ${ }^{45,46}$ have shown that insulin exerts anti-inflammatory activity by inhibiting the secretion pro-inflammatory cytokines IL-1 $\beta$, IL-8 and TNF- $\alpha$. Based on studies cited above ${ }^{44,45,47}$, we can state that insulin treatment in T2D patients, in the present study, might contribute to low numberof total lymphocytes (CD3+ and CD8+ T cells) and high frequency of Treg cells which might be related to low cell-mediated adaptive immunity in these patients, since Treg cells are known to suppress the activation of CD4+ and CD8+ T cells ${ }^{15,16,27,28}$.

In the present study, insulin-treated T2D patients exhibited an increased frequency of B lymphocytes and showed anti-inflammatory profile revealed by high level of circulating IL-10. However, other investigators have reported that $\mathrm{B}$ cells induce insulin resistance, regulate inflammation and promote pro-inflammatory $\mathrm{T}$ cell functions and cytokines in type 2 diabetes 20, 48, which appeared to becontradictory to that we described in this study. To address this dichotomy, we have calculated ratios of B-cell: Teff and B-cell:Treg. We found that the ratio value of T2D patients (B-cell:Teff $=5.27)$ was 1.41-fold of that of control subjects (B-cell:Teff=3.73), and (B-cell:Treg=1.42) of T2D patients was 3.0-fold of that of control subjects (B-cell:Treg=0.47), suggesting that the predominance was in favor of B-cells in T2D patients. Nevertheless, the general idea that we described in this study is that T2D patients showed anti-inflammatory profileand increased B lymphocytes due to insulin treatment, consistent with Th2 phenotype. Be that it may, our results revealed that a cross-talk would exist between insulin level and the number of B lymphocytes in type 2 diabetes mellitus and, this need to be explored.

Furthermore, insulin-treated T2D patients exhibited high frequency of differentiated Teff cells, defined as CD4+Th subpopulation that express CD25+CD127+ and less Foxp-3 protein. Concomitantly, the level of circulating IL-10 (Th2 cytokines) was significantly increased while those of IFN- $\gamma$ and IL- 2 were decreased in T2D patients, suggesting that CD4+ Th0 cells in T2D patients have preferentially differentiated into (IL-10-producing) Th2 effector cells. It is recognized that IL-10 is produced by several types of cells including Treg cells, CD4+Teffh2 cell, Breg cells.... ${ }^{10-13,31,49}$. However, we would like to specify that Treg cells represent $1-3 \%$ of total CD $4+$ T-cells in human ${ }^{27-29}$. Although Treg cells increased in T2D patients, increase of IL-10 would not be attributed only to Treg cell production since CD4 Th2 cells also increased in these patients.

To decide between these two opinions, we calculated the Teff:Treg ratios. We found that the ratio value of T2D patients (Teff:Treg=0.27) is 2.1-fold of that of control subjects (Teff:Treg=0.12), suggesting that the observed increase of IL-10 in T2D patients was in favor of Teff cells. On the one hand, Under these observationconditions described above suggested, we can assume that IL10 comes, in large part, from Teff, cells confirming the preferential differentiation of CD+Th cells into (IL10-producing) Th2 effector cells in insulin-treated T2D patients. Our idea was supported by Th1/Th2 ratios calculated as IL-2/IL-4, IL-2/IL-10, IFN- $\gamma / \mathrm{IL}-4$, IFN- $\gamma /$ IL-10 which demonstrated a down-regulation of Th1 and up-regulation of Th2 profile in T2D patients. In fact, the Th2 profile exhibited by insulin-treated T2D patients is consistent with the anti-inflammatory profile of these patients $^{43-45}$.

To highlight the comparatively enhanced anti-inflammatory profile in T2D patients, we have calculated Th2/Th2 ratio representing IL4/IL10 which declined from control subjects (0.69) to diabetic patients (0.16). These observations suggest that the absolute amount of Th2 cytokines (IL-4 and IL-10) was in favor of IL-10 in patients with diabetes, confirming the anti-inflammatory profile of these patients. Nonetheless, it would be interesting to keep in mind the emerging evidence on the dynamic functional plasticity of Treg cells into either pro-inflammatory or anti-inflammatory effector cells ${ }^{50}$. Thus, it would be logically useful to admit another plausible explanation of the present results. The augmented levels of IL-10 in insulintreated T2D patients might be, on the other hand, the results of cumulative secretion of Treg cells, B cells and Teff cells, since this cytokine increased concomitantly with the enhanced frequencies of these cells observed in T2D patients. Indeed, it has been reported that IL10 is produced by several types of cells including Treg cells, CD4+Teff cell, Breg cells ${ }^{10-13,31,49}$. Although the described dynamic functional plasticity of Treg cells 50 , the 
concomitant increase of Teff cells along with Treg cells maysuggest an anti-inflammatory status in insulin-treated diabetic patients, since Treg cells are known to possess anti-inflammatory properties ${ }^{24-26}$.

Taken together, our study showed that insulin-treated type 2 diabetes mellitus appears to be associated with a down-regulation of immune defense system consistent with increased number of Treg cells and CD4+ Th cell differentiation towards IL-10-producing Teff-cells antiinflammatory Th2 phenotype associated with B cell expansion. To sum-up, our results provide evidence that insulin therapy in T2D patients contributes to normalising dyslipidemia and may confer to these patients antiinflammatory profile with high production of IL-10 and this may probably diminish their susceptibility to certain infections or autoimmune and inflammatory diseases. Further studies are required to explore insulin action in the modulation of inflammatory parameters such as adipocytokines (IL-6, TNF- $\alpha$, adiponectin, leptin...), through $\mathrm{T}$ cell derived-cytokines and differentiation in type 2 diabetes mellitus.

\section{Conflict-of-interest disclosure statement}

All of the authors have nothing to declare as far as the conflict of interest is concerned. The authors also declare no competing commercial interests.

\section{References}

1. American Diabetes Association (ADA). Diagnosis and classification of Diabetes Mellitus. Diabetes Care 2008; 31: 55-60.

2. Chaker L, Falla A, van der Lee SJ, Muka T, Imo D, Jaspers L, et al. The global impact of non-communicable diseases on macro-economic productivity: a systematic review. Eur J Epidemiol 2015;30:357-95.

3. World Health Organization. Definition, diagnosis and classification of diabetes mellitus and its complications. Part 1: Diagnosis and classification of diabetes mellitus. Geneva, World Health Organization Report, 1999 (WHO/NCD/NCS/99.2), p 65.

4. Sathyapalan T, Atkin SL. Is there a role for immune and anti-inflammatory therapy in type 2 diabetes? Minerva Endocrinol 2011; 36: 147-156.

5. Li ZZ, Liu JB, Li L, Jiao L, Chen L. Intensive therapy for diabetes throughinfluence on innate immune system. Med Hypotheses 2009; 72: 675-676 PubMed .
6. Ehses JA, Lacraz G, Giroix MH, Schmidlin F, Coulaud J, Kassis N, et al. IL-1 antagonism reduces hyperglycemia and tissue inflammation in the type 2 diabetic GK rat. Proc Natl Acad Sci U S A 2009;106:13998-14003

7. Pickup JC, Crook MA. Is type II diabetes mellitus a disease of the innate immune system? Diabetologia 1998; 41: 1241-1248.

8. Pickup JC, Mattock MB, Chusney GD, Burt D. NIDDM as a disease of the innate immune system: association of acute phase reactants and interleukin-6 with metabolic syndrome X. Diabetologia 1997; 40: 1286-1292. 9. Ategbo JM, Grissa O, Yessoufou A, Hichami A, Dramane KL, Moutairou K, et al.Modulation of adipokines and cytokines in gestational diabetes and macrosomia. $J$ Clin Endocrinol Metab 2006; 91:4137-43.

10. Khan NA, Yessoufou A, Kim M, Hichami A. N-3 fatty acids modulate Th1 and Th2 dichotomy in diabetic pregnancy and macrosomia. I Autoimmun 2006; 26:268277.

11. Yessoufou A, Hichami A, Besnard P, Moutairou, Khan NA. PPAR $\alpha$ deficiency increases the risk of maternal abortion and neonatal mortality in murine pregnancy with or without diabetes mellitus: modulation of $\mathrm{T}$ cell differentiation. Endocrinology 2006; 147:4410-4418.

12. Yessoufou A, Moutairou K. Maternal diabetes in pregnancy: early and long-term outcomes on the offspring and the concept of "metabolic memory". Exp Diabetes Res. 2011;2011:218598. doi: 10.1155/2011/218598.

13. Yessoufou A, Plé A, Moutairou K, Hichami A, Khan NA. Docosahexaenoic acid reduces suppressive and migratory functions of CD4+CD25+ regulatory T-cells. $J$ Lipid Res 2009; 50:2377-88 PubMed .

14. Baranovski BM, Freixo-Lima GS, Lewis EC, Rider P. T Helper Subsets, Peripheral Plasticity, and the Acute Phase Protein, $\alpha 1$-Antitrypsin. Biomed Res Int. 2015;2015:184574. doi: 10.1155/2015/184574.

15. Rengarajan J, Szabo SJ, Glimcher LH. Transcriptional regulation of Th1/Th2 polarization. Immunol Today 2000; 21: 479-483.

16. Wood SC, Rao TD, Frey AB. Multidose streptozotocin induction of diabetes in $\mathrm{BALB} / \mathrm{cBy}$ mice induces a $\mathrm{T}$ cell proliferation defect in thymocytes which is reversible by interleukin-4. Cell Immunol 1999; 192: 1-12.

17. Liblau RS, Singer SM, McDevitt HO. Th1 and Th2 CD4 $\mathrm{p}$ T cells in the pathogenesis of organ-specific autoimmune diseases. Immunol Today 1995; 16:34e8. 
18. Nishimura S, Manabe I, Nagasaki M, Eto K, Yamashita H, Ohsugi M. CD8+ effector T cells contribute to macrophage recruitment and adipose tissue inflammation in obesity. Nat Med 2009; 15: 914-920.

19. Jagannathan-Bogdan M, McDonnell ME, Shin H, Rehman Q, Hasturk H, Apovian CM. Elevated proinflammatory cytokine production by a skewed T cell compartment requires monocytes and promotes inflammation in type 2 diabetes. J Immunol 2011; 186: 1162-1172.

20. Winer DA, Winer S, Shen L, Wadia PP, Yantha J, Paltser G, et al. B Lymphocytes Promote Insulin Resistance through Modulation of T Lymphocytes and Production of Pathogenic IgG Antibody. Nat Med 2011; 17: 610-617. 21. Chawla A, Nguyen KD, Goh YP. Macrophage-mediated inflammation in metabolic disease. Nat Rev Immunol 2011; 11: 738-749.

22. Lumeng CN, Bodzin JL, Saltiel AR. Obesity induces a phenotypic switch in adipose tissue macrophage polarization. J Clin Invest 2007; 117: 175-184.

23. Wentworth JM, Naselli G, Brown WA, Doyle L, Phipson B, Smyth GK. Pro-inflammatory CD11c+CD206+ adipose tissue macrophages are associated with insulin resistance in human obesity. Diabetes 2010; 59: 1648-1656. 24. Deiuliis J, Shah Z, Shah N, Needleman B, Mikami D, Narula V. Visceral adipose inflammation in obesity is associated with critical alterations in $\mathrm{T}$ regulatory cell numbers. PLoS One 2011 Jan 26; 6(1): e16376. doi: 10.1371/ journal. pone.0016376.

25. Winer S, Chan Y, Paltser G, Truong D, Tsui H, Bahrami J. Normalization of obesity-associated insulin resistance through immunotherapy. Nat Med 2009; 15: 921929.

26. Feuerer M, Herrero L, Cipolletta D, Naaz A, Wong J, Nayer A. Lean, but not obese, fat is enriched for a unique population of regulatory $\mathrm{T}$ cells that affect metabolic parameters. Nat Med 2009; 15: 930-939.

27. Sakaguchi S. Regulatory T cells: key controllers of immunologic self-tolerance. Cell 2000; 101: 455-458.

28. Shevach EM. CD4+ CD25+ suppressor T cells: more questions than answers. Nat Rev Immunol 2002; 2: 389-400. 29. Bluestone JA, Abbas AK. Natural versus adaptive regulatory T cells. Nat Rev Immunol 2003;3: 253-257. Review. 30. Groux H. An overview of regulatory T cells. Microbes Infect 2001; 3: 883-9.

31. Buckner JH, Ziegler SF. Regulating the immune system: the induction of regulatory $\mathrm{T}$ cells in the periphery. Arthritis Res Ther 2004; 6: 215-22 Review.
32. Ibikounlé M, Satoguina J, Fachinan R, Tokplonou L, Batcho W, Kindé-Gazard D, Mouahid G, Moné H, Massougbodji A, Courtin D. Epidemiology of urogenital schistosomiasis and soil-transmitted helminths among schoolchildren of Lake Nokoue areas of Sô-Ava, south Benin. J. Appl. Biosci 2013; 70:5632- 5639.

33. Ibikounlé $M$, Ogouyèmi-Hounto $A$, de Tové YS, Dansou A, Courtin D, Kindé-Gazard D, Mouahid G, Moné H, Massougbodji A. Epidemiology of urinary schistosomiasis among school children in Péhunco area, Northern Benin. Malacological survey. Bull Soc Pathol Exot 2014; 107(3):177-84.

34. Greenberg AS, McDaniel ML. Identifying the links between obesity, insulin resistance and $\beta$-cell function: potential role of adipose- derived cytokines in the pathogenesis of type 2 diabetes. Eur J Clin Invest 2002;32: 24-34. 35. Buggage RR, Matteson DM, Shen de F, Sun B, Tuaillon N, Chan CC 2003 Effect of sex hormones on experimental autoimmune uveoretinitis (EAU). Immunol Invest 32:259-273.

36. Klein SL, Bird BH, Glass GE 2001 Sex differences in immune responses and viral shedding following Seoul virus infection in Norway rats. Am J Trop Med Hyg 65:57-63. 37. Dandona P, Aljada A, Chaudhuri A, Mohanty P, Garg R. Metabolic syndrome: a comprehensive perspective based on interactions between obesity, diabetes and inflammation. Circulation 2005; 111:1448-1454.

38. Catalano PM, Kirwan JP, Haugel- de Mouzon S, King J. Gestational diabetes and insulin resistance: role in short- and long-term implications for mother and fetus. $J$ Nutr 2003; 133: 1674-1683.

39. Farese RV, Yost TJ, Eckel RH. Tissue-specific regulation of lipoprotein lipase activity by insulin/glucose in normal-weight humans. Metabolism 1991; 40: 214-216.

40. Scoppola A, Testa G, Frontoni S, Maddaloni E, Gambardella S, Menzinger G, et al. Effects of insulin on cholesterol synthesis in type II diabetes patients. Diabetes Care 1995; 18: 1362-1369.

41. Feitosa AC, Feitosa-Filho GS, Freitas FR, Wajchenberg BL, Maranhão RC. Lipoprotein metabolism in patients with type 1 diabetes under intensive insulin treatment. Lipids Health Dis 2013; Feb 11;12:15. doi: 10.1186/1476511X-12-15.

42. Muller S, Martin S, Koenig W, Hanifi-Moghaddam P, Rathmann W, Haastert B, et al. Impaired glucose tolerance is associated with increased serum concentrations of interleukin 6 and co-regulated acute-phase proteins 
but not TNF-alpha or its receptors. Diabetologia 2002; 45: 805-812.

43. Zeng C, Shi X, Zhang B, Liu H, Zhang L, Ding W, et al. The imbalance of Th17/Th1/Tregs in patients with type 2 diabetes: relationship with metabolic factors and complications. J Mol Med (Berl) 2012; 90(2):175 PubMed $-86$.

44. Xiu F, Stanojcic M, Diao L, Jeschke MG. Stress Hyperglycemia, Insulin Treatment, and InnateImmune Cells. Int J Endocrinol 2014;2014:486403. doi: 10.1155/2014/486403. 45. Sarigianni M, Bekiari E, Tsapas A. Effect of glucose and insulin on oxidized low density lipoprotein phagocytosis by human monocytes: a pilot study. Angiology 2011; 62: 163-166.

46. Wurm S, Neumeier M, Weigert J. Insulin induces monocytic CXCL8 secretion by the mitogenic signalling pathway. Cytokine 2008; 44: 185-190.
47. Dimitriadis G, Maratou E, Boutati E, Psarra K, Papasteriades C, Raptis SA. Evaluation of glucose transport and its regulation by insulin in human monocytes using flow cytometry. Cytometry Part A 2005; 64: 27-33.

48. DeFuria J, Belkina AC, Jagannathan-Bogdan M, Snyder-Cappione J, Carr JD, Nersesova YR, et al. B cells promote inflammation in obesity and type 2 diabetes through regulation of T-cell function and an inflammatory cytokine profile. Proc Natl Acad Sci U S A. 2013; 110:51335138.

49. Sun J, Wang J, Pefanis E, Chao J, Rothschild G, Tachibana I, et al. Transcriptomics Identify CD9 as a Marker of Murine IL-10-Competent Regulatory B Cells. Cell Rep 2015; 13(6):1110-1117.

50. Campbell DJ, Koch MA. Phenotypical and functional specialization of FOXP3 + regulatory T cells. Nat Rev Immunol. 2011;11(2):119-30. doi: 10.1038/nri2916. 